Original article

\title{
Stress-related mucosal disease: Incidence of bleeding and the role of omeprazole in its prophylaxis
}

\author{
Marta C. Amaral a,b,*, Catarina Favas a , J. Delgado Alves ${ }^{\text {b,c }}$, Nuno Riso a , M. Vaz Riscado ${ }^{\text {a }}$ \\ a Department of Medicine II, Curry Cabral Hospital, Lisbon, Portugal \\ b Pharmacology Department, Faculty of Medical Sciences, Lisbon, Portugal \\ c Department of Medicine IV, Fernando Fonseca Hospital, Amadora, Portugal
}

\section{A R T I C L E I N F O}

\section{Article history:}

Received 19 April 2010

Received in revised form 12 June 2010

Accepted 17 June 2010

Available online 27 July 2010

\section{Keywords:}

Stress-related mucosal disease

Bleeding prophylaxis

Omeprazole

\begin{abstract}
A B S T R A C T
Background: Upper gastrointestinal bleeding is the severe complication of stress-related mucosal disease in hospitalized patients. In intensive care units (ICU), risk factors are well defined and only mechanical ventilation and coagulopathy proved to be relevant for significant bleeding. On the contrary, in non-ICU settings there is no consensus about this issue. Nevertheless, omeprazole is still widely used in prophylaxis of bleeding. The objective of our study was to evaluate the relevance of stress-related mucosal disease bleeding in patients admitted to an internal medicine ward, and the role of omeprazole in its prophylaxis. Methods: We conducted a retrospective study in which we analysed consecutive patients who were admitted to our ward over a year. We recorded demographic characteristics of the patients, potential risk factors for stress-related mucosal disease (clinical data, laboratory, and medication), administration of prophylactic omeprazole, and total cost of this prophylaxis. Patients with active gastrointestinal bleeding on the admission were excluded. We recorded every upper gastrointestinal bleeding event with clinical relevance. Results: Five hundred and thirty-five patients, mean age 70 years, mean length of stay $9.6 \pm 7.7$ days; 140 (26.2\%) patients were treated with $40 \mathrm{mg}$ of omeprazole intravenously, 193 (36.1\%) with $20 \mathrm{mg}$ of omeprazole orally, and $202(37.8 \%)$ patients had no prophylaxis. There was only one episode $(0.2 \%)$ of clinically relevant bleeding.

Conclusion: In patients admitted to an internal medicine ward, incidence of upper gastrointestinal bleeding as a complication of stress-related mucosal disease is low. We found that there is no advantage in prophylaxis with omeprazole.
\end{abstract}

(c) 2010 European Federation of Internal Medicine. Published by Elsevier B.V. All rights reserved.

\section{Introduction}

Stress-related mucosal disease is defined as a superficial lesion most commonly observed in the acid-producing portions of gastric mucosa that can occur after the first $24 \mathrm{~h}$ of hospitalization [1]. Its pathogenesis has not been explained completely but it has been suggested that hypoperfusion of the upper gastrointestinal tract might be crucial [1]. Although stress-related mucosal disease can be the cause of $15 \%$ of all the upper gastrointestinal bleeding events, actual hæmorrhage is only measurable in $6 \%$ of cases, being clinically significant in less than $3 \%$ [2]. In intensive care units (ICU), predisposing conditions for stress-related mucosal disease are prolonged mechanical ventilation, coagulopathy, shock, major trauma, surgery, or burn, and multiple organ failure $[3,4]$. However, randomized trials

\footnotetext{
* Corresponding author. Pharmacology Department, Faculty of Medical Sciences, New University of Lisbon, Campo Mártires da Pátria, 130 1169-056 Lisboa, Portugal. Tel.: + 35121880 3035; fax: + 351218803083.

E-mail address: marta.amaral@fcm.unl.pt (M.C. Amaral).
}

have suggested that only the first two entities might be relevant, as in their absence the incidence of clinical significant bleeding is less than $0.1 \%[4,5]$.

Despite bleeding from stress-related mucosal disease is not an exclusive condition of the critically ill, little is known about its incidence, cause and outcome in non-ICU patients [6]. Although patients are admitted to general medical wards with an increasing number of severe co-morbidities, most of the conditions described above as high risk factors for the development of this complication are infrequent in these patients.

Proton-pump-inhibitors (PPIs) are the most effective agents for reducing gastric acid secretion, being frequently used in many gastrointestinal disorders [7,8]. Nevertheless, evidence of their benefit in the prophylaxis of bleeding from stress-related mucosal disease is lacking. Despite this, omeprazole and other PPIs are commonly used for this purpose, either in critical care or in general medical wards [9].

The aims of our study were to evaluate the incidence of upper gastrointestinal bleeding possibly associated with stress-related mucosal disease in patients admitted to an internal medicine ward, as well as the potential role of omeprazole in its prophylaxis. 


\section{Patients and methods}

Consecutive patients hospitalized in our internal medicine department over a year (from 1st January to 31st December) were retrospectively analysed. Patients were ineligible if they had gastrointestinal bleeding (hæmatemesis, melenæ or hæmatochezia) within $48 \mathrm{~h}$ before or $24 \mathrm{~h}$ after admission. We recorded demographic data length of hospitalization, diagnoses, and number of potential severity criteria [4] at the time of admission such as: moderate to severe infection (core temperature $>38.5^{\circ} \mathrm{C}$ or $<35^{\circ} \mathrm{C}$, and white-cell count $>15,000 / \mathrm{mm} 3$ or $<3000 / \mathrm{mm} 3$ ); hypotension (systolic blood pressure $<80 \mathrm{~mm} \mathrm{Hg}$ for $2 \mathrm{~h}$ or more, or a decrease of $\geq 30 \mathrm{~mm} \mathrm{Hg}$ in it); renal failure (creatinine clearance rate $<40 \mathrm{~mL}$ per minute, $<500 \mathrm{~mL}$ of urine per day, or serum creatinine concentration $>2.8 \mathrm{mg} / \mathrm{dL}$ ), coagulopathy (platelet count $<50,000 / \mathrm{mm} 3$, International Normalized Ratio $>1.5$, or partial-thromboplastin time $>2.0$ times the control value); hepatic failure (any two of the following: serum bilirubin concentration $>8.8 \mathrm{mg} / \mathrm{dL}$, serum aspartate aminotransferase level $>500 \mathrm{U} / \mathrm{L}$, serum albumin $<41 \mathrm{~g} / \mathrm{L}$, and clinical signs and symptoms of hepatic coma); a Glasgow coma score $<5$. We recorded the Karnofsky score of each patient at admission (I-independent for daily activities, II-partially dependent, or III-totally dependent), the administration of glucocorticoids, warfarin, non-fractioned or low molecular weight heparin, anti-platelet agents, and nonsteroidal antiinflammatory drugs (NSAIDs) during hospitalization, and the use of omeprazole only for prophylactic purposes. The treatment regimen was selected according to the best clinical judgement of the consultant in charge in Accident and Emergency Room (A \& E) at the time of admission. Upper gastrointestinal bleeding with clinical relevance was defined as hæmatemesis, gross blood or "coffee grounds" material in a nasogastric aspirate, or melenæ, complicated by a spontaneous decrease of more than $20 \mathrm{~mm} \mathrm{Hg}$ in the systolic blood pressure, an increase of more than 20 beats per minute in the heart rate, or a decrease in the hæmoglobin level of more than $2 \mathrm{~g} / \mathrm{dL}$ [4].

Statistical analysis was performed using SPSS Statistics 17.0, IBM Company. Quantitative data were expressed as means \pm standard deviation (SD). Qualitative data and their association with the treatment groups were analysed using Pearson Chi-Square Test, considering $P$ values $<0.05$ statistically significant.

Calculation of the cost of prophylaxis was made based on the number of tablets or intravenous injections of omeprazole administered during each patient's stay, according to the wholesale price data from the pharmacy of our hospital.
All patients gave consent to participate in the study, which was approved by the local ethics committee.

\section{Results}

Clinical records from 535 patients, 216 (40.4\%) men and 319 (59.6\%) women, mean age $70 \pm 16$ (18-98) years, were analysed. Mean duration of hospitalization was $9.6 \pm 7.7$ days. Among these, 140 (26.2\%) patients were treated with $40 \mathrm{mg}$ of omeprazole intravenously (i.v.) and daily (qd), 193 (36.1\%) were treated with $20 \mathrm{mg}$ of omeprazole orally (p.o.) qd, and 202 (37.8\%) patients did not receive any prophylaxis for stress-related mucosal disease.

There were no differences between the 3 groups of patients concerning baseline characteristics of patients, disease severity, and use of NSAIDs, steroids, and anticoagulation (with warfarin or heparin) at the time of admission (Table 1 ). All the patients were able to eat or were fed enterically, and were breathing spontaneously. When infection was considered there was a difference $(p=0.002)$ between the group who was treated with i.v. omeprazole and the other two groups: in the first group, the number of patients infected was significantly higher. Concerning Karnofsky score there was also a difference $(p=0.008)$ : the number of totally independent patients (score I) who received prophylaxis with i.v. omeprazole was significantly lower. There was a higher number of patients treated with anti-platelet therapy in the group taking oral omeprazole $(p=0.006)$ (Table 1$)$. None of the patients was treated with any other stress-related mucosal disease prophylactic agents. There were no differences in the incidence of nosocomial pneumoniæ in the three groups and there were no infection by Clostridium difficile.

According to price data provided from the hospital's pharmacy, each $20 \mathrm{mg}$ tablet of omeprazole costs $0.16 €$, versus $6.60 €$ of the injectable formulation ( $40 \mathrm{mg}$ ). Considering that patients in the "i.v. group" were treated with i.v. omeprazole at least half of the time during their stay in the ward (700 days), switching to oral omeprazole after that and continuing to be on this regimen until discharge, total cost of prophylaxis reached 5,000,00 €, approximately. This corresponds to an additional spent of $900,00 €$ per 100 patients admitted to our ward.

There was one episode $(0.2 \%)$ of clinically relevant upper gastrointestinal bleeding in a patient from the group who had no prophylaxis $(\mathrm{p}=\mathrm{ns})$.

Table 1

Demographic, clinical and laboratory characteristics of the 3 groups of patients.

\begin{tabular}{|c|c|c|c|c|}
\hline Characteristics of Patients & No prophylaxis & Omeprazole 20 mg po qd & Omeprazole $40 \mathrm{mg}$ iv qd & $P$ value \\
\hline Age, years (mean $\pm S D$ ) & $68 \pm 18$ & $70 \pm 14$ & $72 \pm 14$ & ns \\
\hline Gender (M:F), $n(\%)$ & $80(37): 122(38.2)$ & 72(33.3):121(37.9) & $64(29.6): 76(23.8)$ & ns \\
\hline Length of stay, days (mean \pm SD) & $9.0 \pm 5.1$ & $10.0 \pm 8.7$ & $10.0 \pm 9.1$ & ns \\
\hline Cardiovascular disease, $n(\%)$ & $44(34.1)$ & $50(38.8)$ & $35(27.1)$ & ns \\
\hline Cerebrovascular disease, $n(\%)$ & $40(37.7)$ & $39(36.8)$ & $27(25.5)$ & ns \\
\hline Respiratory disease, $n(\%)$ & $40(35.7)$ & $42(37.5)$ & $30(26.8)$ & ns \\
\hline Gastrointestinal disease, $n(\%)$ & $20(30.3)$ & $27(40.9)$ & $19(28.8)$ & ns \\
\hline Other primary diagnosis, $n(\%)$ & $58(47.5)$ & $35(28.7)$ & $29(23.8)$ & ns \\
\hline Infection, $n(\%)$ & $74(34.3)$ & $68(31.5)$ & $74(34.3)$ & 0.002 \\
\hline Neoplasia, $n(\%)$ & $35(36.1)$ & $32(33.0)$ & $30(30.9)$ & ns \\
\hline \multirow{3}{*}{ Severity criteria, $n$ criteria- $n$ patients (\%) } & $1-20(32.8)$ & $1-20(32.8)$ & $1-21(34.4)$ & ns \\
\hline & $2-2(22.2)$ & $2-3(33.3)$ & $2-4(44.4)$ & \\
\hline & $3-2(40.0)$ & $3-2(40.0)$ & $3-1(20.0)$ & \\
\hline \multirow[t]{3}{*}{ Karnofsky score, $n(\%)$} & $\mathrm{I}-34(47.2)$ & $\mathrm{I}-29(40.3)$ & $\mathrm{I}-9(12.5)$ & 0.008 \\
\hline & II-14(26.9) & II-25(48.1) & II-13(25.0) & \\
\hline & III-35(34.7) & III-32(31.7) & III-34(33.7) & \\
\hline Anti-platelet therapy, $n(\%)$ & $101(32.7)$ & $127(41.1)$ & $81(26.2)$ & 0.006 \\
\hline NSAIDs, $n(\%)$ & $21(37.5)$ & $23(41.1)$ & $12(21.4)$ & ns \\
\hline Anticoagulation, $n(\%)$ & $19(35.2)$ & $23(42.6)$ & $12(22.2)$ & ns \\
\hline Steroids, $n(\%)$ & $18(26.5)$ & $28(41.2)$ & $22(32.4)$ & ns \\
\hline
\end{tabular}

Legend: $n-$ number of; SD-standard deviation; NSAIDs-nonsteroidal antiinflammatory drugs. 


\section{Discussion}

In our population, we found that the incidence of bleeding associated with stress-related mucosal disease was very low. There was no difference amongst the treatment groups concerning the baseline characteristics, and there was no evidence for a benefit in the use of omeprazole for prophylaxis of clinically relevant bleeding.

In the last two decades, several studies have been trying to define factors associated with a high risk for stress-related mucosal disease bleeding, and whether there is a need for its prophylaxis [10-12]. The vast majority of these studies have addressed this issue in an ICUsetting, and by now, despite conflicting data, it is consensual that only patients with respiratory failure requiring prolonged mechanical ventilation and/or coagulopaphy should receive preventive therapy [13]. The recognition of the seriousness of the factors that demand prophylaxis has raised the question of whether this should be made in non-ICU patients, who will naturally lack these clinical syndromes and therefore will have a lower risk for stress-related mucosal disease bleeding. Currently, and in real-life practice, prophylaxis continues to be the standard of care in patients admitted to wards, and PPIs, as the most effective antisecretory agents, incontestably safe, are undoubtedly the universal drug of choice [14].

Only a small number of studies have examined the effectiveness of this prophylactic attitude in non-ICU patients $[9,15]$, as well as its cost impact $[16,17]$, and none were proper prospective controlled studies. These studies have shown a higher incidence of bleeding, but there were major differences in the populations considered in each one. Some of those particular characteristics included patients initially admitted to ICUs $[6,15]$, patients submitted to major surgeries $[16,17]$, including organ transplant [6], and patients with prolonged times of admission (more than 14 days) [6]. All these are relevant factors which are not present in typical medical patients, admitted to internal medicine wards.

Despite being limited by a non-randomized, open-labelled, retrospective design, our study was the first to focus exclusively on an internal medicine ward, analysing several different variables presumably implicated as risk factors for stress-related mucosal disease bleeding, during an extended period of time (a whole year), and with one of the largest reported cohorts. Although the decision to begin prophylaxis relied on a subjective clinical judgement, we found that most of the baseline characteristics of the patients were homogeneous among the three groups, which made them comparable between each other. There were two exceptions: patients treated with i.v. omeprazole presented a significantly higher percentage of infection and a lower percentage of independency for daily activities; and the "p.o. group" had a higher percentage of patients treated with antiplatelet drugs. The former finding may be explained by the assumption of the consultant at admission that more seriously ill patients, frequently infected and dependent, would need prophylaxis and were unable to swallow a tablet or had an impaired gastrointestinal absorption. Nevertheless, this difference did not change the outcome of these patients, (regarding bleeding incidence), significantly.

Another issue is whether administration of drugs like NSAIDs, antiplatelet or anticoagulant agents, or steroids represents an increased risk for stress-related mucosal disease bleeding. It is widely known that use of NSAIDs increases the risk of upper gastrointestinal bleeding 4 to 5 -fold, and that this complication has a cumulative incidence of $0.9-1.4 \%$ after 12 months of NSAID exposure [18]. Concerning the other previously referred drugs, prognostic numbers are not so accurate but it is generally accepted that the highest risk lies on the coexistence of two or more factors like age, prior bleeding events or association of two of these pharmacological groups [19]. In our study, most of the patients had co-morbidities and were being treated with at least one of these drugs. Nevertheless, even if a significant risk exists, the short time of admission lowers the probability of the occurrence of relevant bleeding.

Finally, extrapolation of costs suggests that prophylaxis of bleeding might have a significant economic impact.

In conclusion, we found that there is no advantage in the use of omeprazole in preventing stress-related mucosal disease bleeding. This seems to be mainly due to the low incidence of clinically relevant bleeding, rather than a lack of efficacy of omeprazole in its prophylaxis.

\section{Learning points}

- Patients admitted to an internal medicine ward have a low incidence of stress-related mucosal disease bleeding.

- There is no advantage in the use of omeprazole for the prevention of clinically relevant bleeding in this context.

\section{References}

[1] Stollman N, Metz DC. Pathophysiology and prophylaxis of stress ulcer in intensive care unit patients. J Crit Care 2005;20:35-45.

[2] Duerksen DR. Stress-related mucosal disease in critically ill patients. Best Pract Res Clin Gastroenterol 2003;17:327-44.

[3] Schuster DP, Rowley H, Feinstein S, McGue MK, Zuckerman GR. Prospective evaluation of the risk of upper gastrointestinal bleeding after admission to a medical intensive care unit. Am J Med 1984;76:623-30.

[4] Cook DJ, Fuller HD, Guyatt GH, Marshall JC, Leasa D, Hall R, et al. Risk factors for gastrointestinal bleeding in critically ill patients. N Engl J Med 1994;330:377-81.

[5] Cook DJ, Guyatt G, Marshall J, Leasa D, Fuller H, Hall R, et al. A comparison of sucralfate and ranitidine for the prevention of upper gastrointestinal bleeding in patients requiring mechanical ventilation. N Engl J Med 1998;338:791-7.

[6] Terdiman JP, Ostroff JW. Gastrointestinal bleeding in the hospitalized patient: a case-control study to assess risk factors, causes, and outcome. Am J Med 1998;104: 349-54.

[7] Metz DC. Potential uses of intravenous proton pump inhibitors to control gastric acid secretion. Digestion 2000;62:73-81.

[8] Brett S. The use of proton pump inhibitors for gastric acid suppression in critical illness. Crit Care 2005;9(1):45-50.

[9] Nardino RJ, Vender RJ, Herbert PN. Overuse of acid-suppressive therapy in hospitalized patients. Am J Gastroenterol 2000;95:3118-22.

[10] Cook DJ, Pearl RG, Cook RJ, Guyatt GH. Incidence of clinically important bleeding in mechanically ill ventilated patients. J Intensive Care Med 1991;6:167-74.

[11] Shuster DP. Stress ulcer prophylaxis: in whom? With what? Crit Care Med 1993;21:4-6.

[12] Zandstra DF, Stoutenbeek CP. The virtual absence of stress ulceration related bleeding in ICU patients receiving prolonged mechanical ventilation without any prophylaxis: a prospective cohort study. Intensive Care Med 1994;20:335-40.

[13] ASHP Commission on Therapeutics. AHSP guidelines on stress ulcer prophylaxis. Am J Health Syst Pharm 1999;56:347-79.

[14] Grube RR, May DB. Stress ulcer prophylaxis in hospitalized patients not in intensive care units. Am J Health Syst Pharm 2007;64:1396-400.

[15] Parente F, Cucino C, Gallus S, Bargiggia S, Greco S, Pastore L, et al. Hospital use of suppressive medications and its fall-out on prescribing in general practice: a 1 month survey. Aliment Pharmacol Ther 2003;17:1503-6.

[16] Heidelbaugh JJ, Inadomi JM. Magnitude and economic impact of inappropriate use of stress ulcer prophylaxis in non-ICU hospitalized patients. Am J Gastroenterol 2006;101:2200-5.

[17] Nasser SC, Nassif JG, Dimassi HI. Clinical and cost impact of intravenous proton pump inhibitor use in non-ICU patients. World J Gastroenterol 2010;16(8):982-6.

[18] Lanas A. Nonsteroidal anti-inflammatory drugs, low-dose aspirin, and potential ways of reducing the risk of complications. Eur J Gastroenterol Hepatol 2001;13 (6):623-6.

[19] Lanza FL, Chan FKL. and the Practice Parameters Committee of the American College of Gastroenterology. Guidelines for Prevention of NSAID-Related Ulcer Complications. Am J Gastroenterol 2009;104:728-38. 